\title{
Research on the Information Resources Integration Based on the Big Data Platform
}

\author{
Yin Lei, Jiahong Zhong \\ Gannan Medical University, Ganzhou, 341000, China
}

Keywords: Big data, Information resources, Resources integration

\begin{abstract}
Big data platform can integrate the mass data in some certain ways to unearth products and services of huge values to promote the economic and social change. This paper analyzes the characteristics of the information resources in the era of big data, and explores the integration models of information resources of the three organizations, which are governments, universities and hospitals, to provide some references for the relevant researchers.
\end{abstract}

\section{Introduction}

With the rapid development of mobile network technology, information resources are also quietly integrated into people's daily lives, and imperceptibly influence people's lives. Examine the influence caused by Internet technology on people's life: in the big data era, the rapid development of the Internet continues to change people's daily behavior, common consumption patterns of reading, communication, etc. in daily life can be achieved through mobile Internet, digital information society value reflected therefrom. People's awareness of resources has been strengthened, and the efficiency of information resources has also increased rapidly. The rich information resources access channels have brought convenience to users. With the development of information resources management, classification and the distinction between commercial and non-commercial information resources, a series of development problems have been plagued by the managers of information resources. In the era of big data, users through information access to information resources when we can define it as the information resource consumers, but when the user through the network platform to spread their ideas and knowledge, we can also be regarded as the user information, user participation in innovation information resources will help spread on information resources. Born in the network environment, we cannot evaluate the authenticity and reliability of the information resources. Under the development trend of big data, there is a strong replication of information resources. By means of network technology, we can copy the information resources of others into their own resources. This kind of behavior often appears in the commercial information resources. This phenomenon is also the data information resources of the disorder, the development of clutter foreshadowed. Therefore, with the advent of the era of data, in the face of the growth of information resources, we must strengthen the integration of information resources.

\section{Features of Information Resources in the Big Data Era}

Mass Characteristic. Information resources is the crystallization of human wisdom and ability, it is intangible assets, which has the ability to grow, is in the process of continuous development and utilization in the process of continuous enrichment, growth, inexhaustible. And the general material resources, such as mineral resources, can only be the development and utilization of resources less, some scarce resources will even dry up. The growth of information resources, people should not only pay attention to the use of information resources, but also pay more attention to the development and development of information resources. In the modern information society, the strength and level of the research and development of information resources has become a prominent symbol of the development of social productive forces, and even become an important measure of social progress. In fact, it is in the process of continuous development and utilization of information resources to continuously improve their ability to understand the world and transform the world. The amount of 
information increasing, continuous improvement of the level of information, not only to promote the development of society, power of a huge number of network information resources from all walks of life, including all kinds of information from different disciplines, different areas, different regions, different languages, its content is very rich, which exists in the text, images, audio, video the database, software, etc. The Internet has changed the process of information release and evaluation, the distribution of network information has a great degree of freedom and randomness, the lack of the necessary quality control and management mechanisms. A variety of false information, poor information flooded the Internet, the degree of information pollution, information content. The Internet is open, through the agreement will be linked to different networks, the organization and management of network information resources, there is no uniform standards and norms. Information is widely distributed in different regions of the server, the server has different operating systems and processing methods.

Sharing Characteristic. Resource interactivity is one of its remarkable characteristics. As everyone knows, before the mobile Internet technology to achieve universal basic development, less user access to information, but also belong to the passive acceptance, in most cases, local TV and Radio University or society winter library and other channels to obtain information, and between the user and the information service users to produce good communication AC. In the fast-paced life environment, information service mode in the information resource services is difficult to meet the needs of readers of the traditional information resources, in order to adapt to the development and change of the times, to meet the information needs of users in many aspects, under the support of mobile Internet technology, the network technology based on the new information service mode of information service market quietly the interaction and sharing features improved significantly. The objective existence of differences between industry, industry, business, there is no information difference can be avoided, the emergence of the information gap at present, this gap still did not get effective solution, and are constantly increasing, has become a major factor hindering the block line of sight of people sharing information resources. By the user's favorite micro-blog, WeChat, blog and forums and other information resources access channels, allowing users to quickly and accurately access their own information resources through the service agencies. It can be published through the platform or the body to open the port of personal information on the views and views, and their own ideas on the platform, to achieve the sharing of information resources with other users. In the derivation of a new information technology at the same time, the service provider and the user, the number of users and the number of users and the communication between the quality and significantly improved, to bring convenience to users.

Fast Characteristic. With the development of science and technology, fast is the normal life of people. In the rapid development of mobile Internet technology today, fast pace of life, the rapid change of information, rapid economic development and other social phenomena are explained by the changes brought about by the development of science and technology. To a large extent, the pace of internationalization of China's development, but in the market economy system, the competition pressure between major industries also increased significantly. Look at the mobile Internet technology popularization and development of the reality of industrial development under the globalization, domestic enterprises in the market economy environment, not only need to face the competition between domestic enterprises of the same, also need to face the strong invasion of foreign enterprises, the competition pressure as can be imagined. As everyone knows, the major industry in the development of society at the beginning of the development of major industries and enterprises cannot access their core competitiveness, but from the human capital perspective, to enhance the productivity and ultimately human resources support, resulting in high strength, under the pressure of life in the fast-paced living environment of information users for information resources. The demand continues to rise, and the information resources service from mobile Internet technology development based on the one hand it can effectively meet the user requirements, through the transmission of changes in the way of information, shorten the information service process, such as the traditional winter library information service, users need to check into the museum itself knowledge required, and big data era of information service without this link. The way of information 
transmission is efficient and rapid, and it also improves the utilization ratio of information resources. Rapid transmission of information resources has become the new normal.

\section{Different Integration Models of Information Resources in Different Fields Based on the Big Data Platform}

Integration of Information Resources of Governments. The integration of government information resources, we must consummate the appropriate institutional regulations, building system integration and utilization of information resources, strengthen information resources management responsibilities at all levels of government information and information resources, a clear division of responsibilities of relevant departments. At the same time, the government should strengthen the working mechanism of government information resources life cycle management, innovation management and capital investment, government information resources construction funds should be determined by the competent department of the government information unified use and distribution. The government plans to organize the construction of all kinds of information resources projects, to maximize the integration of the development and utilization of various types of information resources. Integration and utilization of government information resources involves many fields and industries and departments, but because of the complex administrative system and the current decentralized departments of information, if it is unable to achieve expected effect therefore to strengthen the development of information resources by relying solely on one or several independent departments must be unified, the establishment of government information resource management institutions. Governments at all levels according to the establishment of large data center management actual needs, and by these institutions to integrate the use of the system planning, data integration and utilization of unified standards, the specific work and is responsible for the integration and application of government information resources. On the basis of overall planning, the government should be guided by the government and the market operation, division of labor and innovation mode. To carry out the government information resources integration and utilization, and ultimately ensure that organized and effectively deal with all kinds of government information resources, promote the integration of the value of mining and comprehensive application of government information resources, so as to enhance the comprehensive management ability of information resources. The application platform of government information resources integration is an infrastructure of e-government construction, and also is the basic project of building a modern country.

Integration of Information Resources of Universities. The database system refers to the collection and arrangement of the data flow and the response time of the database. The fundamental goal is to improve the utilization of server hardware resources in order to enhance the user experience satisfaction. In addition, with the help of data analysis technology can also understand the specific situation of the University in asset management over the years. This is a great help for the later decision-making. Students are the core of the school. The school needs to carry on the management to each student's specific situation, uses the statistical way to take the specialty, the grade, the class and grade as the division standard to carry on the information conformity. The system will be the birth of the family situation and the location of the school after graduation, etc., can provide greater help for college admissions. Influence of the era of big data, in the current environment is facing many opportunities and challenges especially in the big data environment, the construction of university information system need to fully understand the concept and advantage of big data, which is of great help for data mining and data storage. Resource integration layer as the middle part of the whole architecture, one of the indispensable part in the construction process of the platform is usually at the same time, this section contains two parts database and index database, in the process of resource metadata operation, relates to the tool type is also more, such as cataloging tools are tools and metadata generation tool. In the process of operation, resource integration layer can be integrated with the classification of the various departments of information resources, and the use of standardized way to build information resources view, its basic goal is to manage the information 
resources effectively to achieve simplification and optimization. This is very important for application layer and access layer.

Integration of Information Resources of Hospitals. With the development of science and technology, fast is the normal life of people. In the rapid development of mobile Internet technology today, fast pace of life, the rapid change of information, rapid economic development and other social phenomena are explained by the changes brought about by the development of science and technology. To a large extent, the pace of internationalization of China's development, but in the market economy system, the competition pressure between major industries also increased significantly. The mobile Internet technology popularization and development of the reality of industrial development under the globalization, domestic enterprises in the market economy environment not only need to face the competition between domestic enterprises of the same, also need to face the strong invasion of foreign enterprises, the competition pressure as can be imagined. As everyone knows, the major industry in the development of society at the beginning of the development of major industries and enterprises cannot access their core competitiveness, but from the human capital perspective, to enhance the productivity and ultimately human resources support, resulting in high strength, under the pressure of life in the fast-paced living environment of information users for information resources. The demand continues to rise, and the information resources service from mobile Internet technology development based on the one hand it can effectively meet the user requirements, through the transmission of changes in the way of information, shorten the information service process, such as the traditional winter library information service, users need to check into the museum itself knowledge required, and big data era of information service without this link. The way of information transmission is efficient and rapid, and it also improves the utilization ratio of information resources. Rapid transmission of information resources has become the new normal.

\section{Conclusion}

Big data is of great significance in the integration of information resources. The integration of information resources can dig out huge data value and make full use of it in the massive miscellaneous information resources. All the organizations in the society, including the governments, universities, hospitals, banks, enterprises and others must follow up the development of the big data era to improve the products and services under the concept of information integration.

\section{References}

[1] Cao Di, Yuan Jie, Business Value of Integration and Big Data Era of Information Resources [J]. Science Technology and Industry, 2017, 17(3): 74-78+123.

[2] Yao Guozhang, Liu Zhongxiang, The integration and utilization of government information resources in the background of big data [J]. Journal of Nanjing University of Posts and Telecommunications (Social Science), 2015, 17(4): 20-25.

[3] Huang He, Su Huanqun, He Lian, Zheng Lirong, Economic benefits of developing and sharing medical information resources in big data environment [J]. Chinese Journal of Medical Library and Information Science, 2016, 25(8): 70-72.

[4] Qiang Dongqiang, Proposition to Build the Colleges Information Resources Libraries in the Environment of Big Data, Journal of Jixi University, 2016, 16(5): 39-42. 